\title{
Defective regulation of gap junctional coupling in cystic fibrosis pancreatic duct cells
}

\author{
Marc Chanson, Isabelle Scerri, and Susanne Suter \\ Laboratory of Clinical Investigation III, Department of Pediatrics, University of Geneva, 1211 Geneva 14, Switzerland \\ Address correspondence to: Marc Chanson, Laboratory of Clinical Investigation III, Department of Pediatrics, \\ University Hospital, PO Box 14, Micheli-du Crest 24, 1211 Geneva 14, Switzerland. Phone: 41-22-37-24-609; \\ Fax: 41-22-37-24-088; E-mail: Marc.Chanson@hcuge.ch. \\ Received for publication October 28, 1998, and accepted in revised form May 14, 1999.
}

\begin{abstract}
The cystic fibrosis (CF) gene encodes a cAMP-gated $\mathrm{Cl}^{-}$channel (cystic fibrosis transmembrane conductance regulator [CFTR]) that mediates fluid transport across the luminal surfaces of a variety of epithelial cells. We have previously shown that gap junctional communication and $\mathrm{Cl}^{-}$secretion were concurrently regulated by cAMP in cells expressing CFTR. To determine whether intercellular communication and CFTR-dependent secretion are related, we have compared gap junctional coupling in a human pancreatic cell line harboring the $\Delta$ F508 mutation in CFTR and in the same cell line in which the defect was corrected by transfection with wild-type CFTR. Both cell lines expressed connexin 45 (Cx45), as evidenced by RT-PCR, immunocytochemistry, and dual patch-clamp recording. Exposure to agents that elevate intracellular cAMP or specifically activate protein kinase $\mathrm{A}$ evoked $\mathrm{Cl}^{-}$currents and markedly increased junctional conductance of CFTR-expressing pairs, but not in the parental cells. The latter effect, which was caused by an increase in single-channel activity but not in unitary conductance of $\mathrm{Cx} 45$ channels, was not prevented by exposing CFTR-expressing cells to a $\mathrm{Cl}^{-}$channel blocker. We conclude that expression of functional CFTR restored the cAMP-dependent regulation of junctional conductance in CF cells. Direct intercellular communication coordinates multicellular activity in tissues that are major targets of CF manifestations. Consequently, defective regulation of gap junction channels may contribute to the altered functions of tissues affected in CF.
\end{abstract}

J. Clin. Invest. 103:1677-1684 (1999).

\section{Introduction}

Cystic fibrosis (CF), the most common autosomal recessive disease among Caucasians, is characterized by severely altered functions of adsorbing and secreting epithelia, including chronic suppurative lung disease, pancreatic fibrosis that usually leads to exocrine pancreatic failure, and high concentrations of electrolytes in sweat (1). Although the genetic defect responsible for CF is caused by mutations of the gene coding for cystic fibrosis transmembrane conductance regulator (CFTR), a cAMP-activated, nucleotide trisphosphate-regulated $\mathrm{Cl}^{-}$channel in the apical membrane of epithelial cells (2-5), the pleiotropic manifestations of $\mathrm{CF}$ remain unclear.

Evidence is accumulating that failure of the apical $\mathrm{Cl}^{-}$ channel is not solely responsible for the complex manifestations of the disease. Among the various roles of CFTR within the epithelial cells, it has been demonstrated that the anionic conductance also acts as a regulator of other membrane channels. Indeed, outward rectifying $\mathrm{Cl}^{-}$channels (ORCC) cannot be activated by cAMP in CF airway cells, an anomaly that can be corrected by expression of wild-type CFTR (6-8). Later studies have demonstrated that CFTR also modulates the cAMP-dependent regulation of amiloride-sensitive $\mathrm{Na}^{+}$ channels $(\mathrm{ENaC})$ and activation of $\mathrm{K}^{+}$channels in various epithelial cell types (9-12). More recently, it has been reported that regulation of intestinal $\mathrm{HCO}_{3}{ }^{-}$is impaired in CF mice $(13,14)$. The mechanisms by which CFTR coordinates the regulation of all of these independent ion transporters remain, however, a matter of debate.

Experimental approaches aimed at correcting the CF defect by expression of wild-type CFTR have revealed that correction of as few as $6-20 \%$ of CF cells is sufficient to restore their normal fluid transport properties (15, 16). It has been hypothesized that ionic coupling via gap junctions may serve as the mechanism for amplification of the functional effects of the corrected cells (15). Gap junctions, by mediating the intercellular diffusion of second messengers and small metabolites, indeed provide a pathway to coordinate multicellular activity. In keeping with this view, several studies have shown that agents that activate or inhibit CFTR activity in various epithelial cells also alter their capability for intercellular communication (17-19). Conversely, disruption of gap junctional communication has been associated with altered functions in tissues in which manifestations of $\mathrm{CF}$ occur (20-23). However, whether epithelial cells devoid of functional CFTR exhibit abnormal intercellular communication is not known.

To address this question, we have studied basal and cAMP-stimulated $\mathrm{Cl}^{-}$and gap junctional currents in a human pancreatic cell line (CFPAC-1) harboring the $\Delta$ F508 mutation of CFTR and have compared responses in the same cell line transfected with wild-type CFTR cDNA $(24,25)$. We show in this study that expression of functional CFTR correlates with a reduction in the extent of cell-cell coupling and restores the normal cAMP-dependent regulation of gap junctional coupling. 


\section{Methods}

Cell culture. SKHep1, T84, and CFPAC-1 cells were purchased from the American Type Culture Collection (Rockville, Maryland, USA); PLJ-CFTR cells, a clone of CFPAC-1 cells stably transfected with wild-type CFTR (25), were provided by M. Fanjul (Université Paul Sabatier, Toulouse, France) with the permission of R.A. Frizzell (University of Pittsburgh, Pittsburgh, Pennsylvania, USA). SKHep 1 cells were maintained in DMEM. T84 cells were maintained in 1:1 (vol/vol) DMEM/F-12 medium, and CFPAC-1 and PLJ-CFTR cells were maintained in RPMI-1640 medium. All media were supplemented with $10 \%$

\section{a}
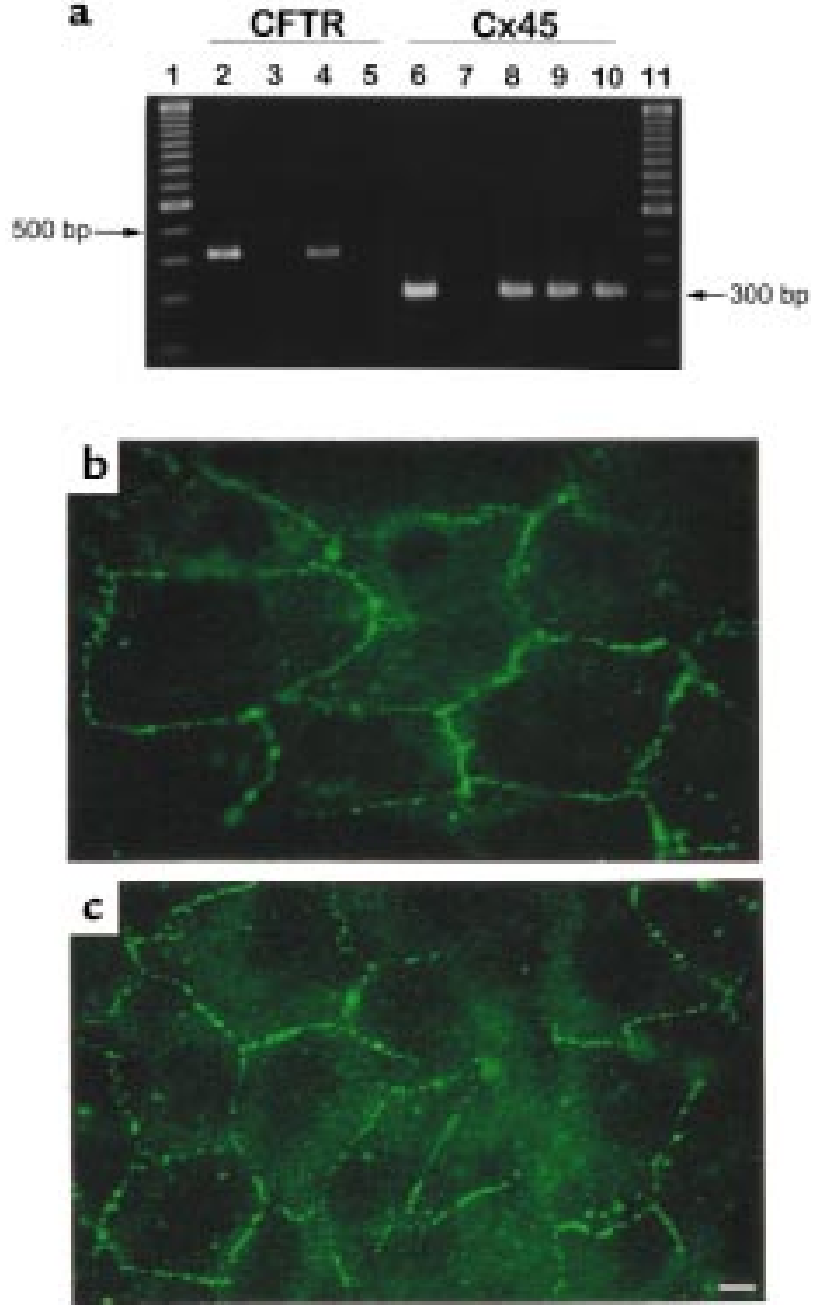

Figure 1

Expression of CFTR and Cx45 in CFPAC-1 and PLJ-CFTR cells. (a) RTPCR of mRNA isolated from both cell lines, as well as from T84, CAPAN, and SKHep1 cells, using primer pairs specific for CFTR (lanes 2-5) and Cx45 (lanes 6-10). Amplification products of the expected sizes for CFTR (expected size: $410 \mathrm{bp}$ ) were detected in T84 and PLJ-CFTR cells (lanes 1 and 4, respectively). No products were detected with these primers in CFPAC-1 and SKHep1 cells (lanes 3 and 5, respectively). mRNA for Cx45 (expected size: 309 bp) was detected in CAPAN, CFPAC-1, PLJ-CFTR, and SKHep1 cells (lanes 6, 8, 9, and 10, respectively), but not in T84 cells (lane 7). Molecular markers are shown in lanes 1 and 11 (b and $\mathbf{c}$ ). Indirect immunofluorescence of CF and corrected pancreatic duct cells cultured on glass coverslips. Punctate labeling for Cx45 was detected in CFPAC-1 (b) and PLJ-CFTR (c) cell clusters at cell-cell contacts. Scale bar: $60 \mu \mathrm{m}$.
FCS, $30 \mathrm{U} / \mathrm{mL}$ penicillin, and $30 \mu \mathrm{g} / \mathrm{mL}$ streptomycin. PLJCFTR cells were continuously selected in the presence of 1 $\mathrm{mg} / \mathrm{mL}$ neomycin, as reported previously (25).

RNA isolation and RT-PCR. Cellular mRNA was isolated from cell lines using oligo-dT columns (Pharmacia Biotech, Dübendorf, Switzerland), according to the manufacturer's instructions. Reverse transcription was carried out using random hexamers, and the resulting cDNA was amplified by PCR using the following primer pairs: for connexin 45 (Cx45): sense 5'-GGAGCACGGTGAAGCAGAC and antisense 5'-CGGGTGGACTTGGAAGCCA (predicted size: 309 bp); for CFTR: sense (exon 3) 5'AGAATGGGATAGAGAGCTGGCTTC and antisense (exon 5) 5'-TTCATCAAATTTGTTCAGGTTGTTG (predicted size: 410 bp). After a 5 -minute start at $94^{\circ} \mathrm{C}$, amplification of CFTR cDNA was carried out for 35 cycles, each comprising 1 minute at $94^{\circ} \mathrm{C}, 1$ minute at $55^{\circ} \mathrm{C}$, and 1 minute at $72^{\circ} \mathrm{C}$, using an UNOII PCR cycler (Biometra GmbH, Göttingen, Germany). After the last cycle, an elongation step of 5 minutes at $72^{\circ} \mathrm{C}$ was performed. To detect connexin mRNAs, 2 rounds of PCR amplification with 31 cycles were used (26). Amplified DNA fragments were separated in a $2 \%$ agarose gel and viewed after ethidium bromide staining. No products were amplified in the absence of reverse transcriptase (not shown).

Immunofluorescence. For immunofluorescent labeling, cell lines were cultured on glass coverslips and fixed for 2-3 minutes with methanol at $-20^{\circ} \mathrm{C}$. The coverslips were rinsed and incubated successively with $0.2 \%$ Triton $\mathrm{X}-100$ for 1 hour, $0.5 \mathrm{M} \mathrm{NH}_{4} \mathrm{Cl}$ for 15 minutes, and PBS supplemented with $2 \%$ BSA for another 30 minutes. Cells were then rinsed and incubated overnight with polyclonal antibodies (diluted 1:100) raised against $\mathrm{Cx} 45$. The Cx45 antibodies were provided by N.J. Severs (Imperial College School of Medicine at National Heart \& Lung Institute, London, United Kingdom; ref. 27). After rinsing, the coverslips were incubated with secondary antibodies conjugated to FITC for 4 hours. Coverslips were examined using a Zeiss Axiophot photomicroscope (Carl Zeiss, Oberkochen, Germany) equipped for fluorescence, and immunostained cells were scanned with a high-sensitivity Photonic Science Coolview camera (Carl Zeiss) connected to a 486DX2/66 Intel PC. Images were captured using the software package Image Access 2.04 (Imagic, Zurich, Switzerland), processed using Adobe Photoshop 3.0.5 (Adobe Systems Inc., Mountain View, California, USA), and printed with a digital Pictrography 4000 printer (Fuji Film, Tokyo, Japan).

CFTR-dependent $\mathrm{Cl}^{-}$currents. CFTR-dependent $\mathrm{Cl}^{-}$currents were measured using the whole-cell configuration of the patch-clamp technique. Cells were cultured on Petri dishes, transferred to the stage of an inverted TMD300 microscope (Nikon AG, Küsnacht, Switzerland), and attached to a threeline perfusion system. Patch electrodes (2-6 M $\Omega$ ) were filled with a solution containing (in $\mathrm{mM}$ ) $1 \mathrm{NaCl}, 138 \mathrm{KCl}, 2.9$ $\mathrm{CaCl}_{2}$, 5.5. EGTA, $3 \mathrm{MgATP}$, and 0.1 GTP, buffered to $\mathrm{pH} 7.2$ with $10 \mathrm{mM}$ HEPES-KOH; ATP and GTP were added to the pipette solution to prevent the rapid rundown of CFTRdependent $\mathrm{Cl}^{-}$currents (8). Throughout the recordings, cells were superfused with a solution containing (in $\mathrm{mM}$ ) $67 \mathrm{NaCl}$, $67 \mathrm{Na}$-gluconate, $7 \mathrm{KCl}, 5 \mathrm{NaHCO}_{3}, 2.5 \mathrm{CaCl}_{2}, 1.2 \mathrm{MgSO}_{4}$, and 2.5 glucose, buffered to $\mathrm{pH} 7.4$ with $12.5 \mathrm{mM}$ HEPES$\mathrm{NaOH} ; 50 \mathrm{mM}$ sucrose was added to bath solutions to prevent swelling-activated $\mathrm{Cl}^{-}$currents (8). Junction potentials were nulled immediately before seal formation. After the establishment of the whole-cell configuration, cells were held at $-70 \mathrm{mV}$ (the reversal potential for $\mathrm{K}^{+}$) and depolarized to $+20 \mathrm{mV}$ (the reversal potential for $\mathrm{Cl}^{-}$) for 200 milliseconds. A mixture of $500 \mu \mathrm{M}$ 8-bromo-cAMP (8-Br-cAMP), $500 \mu \mathrm{M} 8$ (4-chlorophenylthio)-cAMP (CPT-cAMP), and $10 \mu \mathrm{M}$ forskolin was then added to the external solution. Currents were stimulated and recorded routinely for up to 15 minutes. Thereafter, this bath solution was supplemented with 
200-500 $\mu \mathrm{M}$ diphenylamine carboxylic acid (DPC), a $\mathrm{Cl}^{-}$ channel blocker (28). Forskolin and DPC were maintained as stock solutions in DMSO and 100\% ethanol, respectively. These agents were added to the bath solution at the appropriate final concentrations. All currents and voltage signals were acquired at a $2-\mathrm{kHz}$ sampling rate using Pulse software connected to an EPC-9 patch-clamp amplifier (Heka Elektronik, Lambrecht, Germany), and stored on the hard disk of a PowerMacintosh computer (Apple Computer, Inc, Cupertino, California, USA). For off-line analysis of the data, the average membrane current recorded at $-70 \mathrm{mV}$ was calculated for each sweep and expressed as a function of time. Final displays of the traces were generated using the IGOR software (WaveMetrics Inc., Lake Oswego, Oregon, USA).

Cell-coupling measurements. For dye coupling studies, 1 cell within a cluster was impaled with thin-tip microelectrodes filled with a $4 \%$ Lucifer yellow (Sigma Chemical Co., St. Louis, Missouri, USA) solution prepared in $150 \mathrm{mM} \mathrm{LiCl}$ and buffered to $\mathrm{pH} 7.2$ with $10 \mathrm{mM}$ HEPES-KOH. The tracer was allowed to fill the cells by simple diffusion for 3 minutes. At the end of the injection, the electrode was removed and the number of fluorescent cells was counted.

For electrical coupling studies, the dual whole-cell patchclamp approach was applied on pairs of cells to monitor gap junctional conductance. Both cells of a pair were voltage clamped at a common holding potential of $0 \mathrm{mV}$ using the EPC-9 amplifier and a PC-501A amplifier (Warner Instrument Corp., Hamden, Connecticut, USA). To measure gap junctional currents $\left(\mathrm{I}_{\mathrm{j}}\right)$, transjunctional potential differences $\left(\mathrm{V}_{\mathrm{j}}\right)$ were elicited by changing the holding potential of 1 member of a cell pair. $\mathrm{I}_{j}$ was defined as the current recorded in the cell kept at a $0 \mathrm{mV}$. Junctional conductance $\left(\mathrm{g}_{\mathrm{j}}\right)$ was then calculated by $g_{j}=I_{j} / V_{j}$. Series resistance was not compensated and was less than $2 \%$ of the combined junctional and cell input resistances. Cell pairs exhibiting junctional currents that could be measured while applying $\mathrm{V}_{j}$ of $10 \mathrm{mV}$ were defined as coupled. In the remainders, or in pairs in which $g_{j}$ was pharmacologically reduced with the gap junction blocker halothane (29), gating of single gap junction channels could be detected with $V_{j}$ of $35-85 \mathrm{mV}$. Digitized current traces were filtered at $0.1-1.0 \mathrm{kHz}$ for analysis and display of single-channel activity using customized software (MacDAQ; kindly provided by A.C.G. van Ginneken, University of Amsterdam, Amsterdam, the Netherlands). To determine unitary gap junctional conductances $\left(\gamma_{j}\right)$, the amplitudes of single-channel transitions were measured and divided by the applied Vj. Conductance values were then converted into step-amplitude histograms with a bin width of $4 \mathrm{pS}$. Peak values of the singlechannel conductance distributions were determined by fitting the data to Gaussian distributions using IGOR software; results obtained from the fits are expressed as mean \pm SD. For dual patch-clamp experiments, pipettes were filled with a solution containing (in $\mathrm{mM}$ ): $135 \mathrm{CsCl}, 0.5 \mathrm{CaCl}_{2}, 5.5 \mathrm{EGTA}$, $3 \mathrm{MgATP}$, and $0.1 \mathrm{GTP}$, buffered to $\mathrm{pH} 7.2$ with $10 \mathrm{mM}$ $\mathrm{HEPES}-\mathrm{CsOH}$. $\mathrm{CsCl}$ was chosen to replace $\mathrm{KCl}$ in these experiments in order to improve resolution of single gap junction channels by reducing activity of nonjunctional channels. The bath solution contained (in $\mathrm{mM}$ ) $136 \mathrm{NaCl}, 4 \mathrm{KCl}, 1 \mathrm{CaCl}_{2}, 1$ $\mathrm{MgCl}_{2}$, and 2.5 glucose and was buffered to $\mathrm{pH} 7.4$ with 10 $\mathrm{mM}$ HEPES-NaOH. Stimulation of protein kinase A (PKA) was either performed by adding $100 \mu \mathrm{M}$ of the $\mathrm{S}_{\mathrm{p}}$ diastereomer of adenosine- $3^{\prime}, 5^{\prime}$-cyclic monophosphothioate $\left(\mathrm{S}_{\mathrm{p}}-\right.$ cAMPS; Biolog, Bremen, Germany) directly to the intracellular solution immediately before use, or by adding the cAMP cocktail to the external solution. All experiments, representing recordings from about 100 cell pairs, were performed at room temperature. All data were expressed as mean \pm SEM and are compared using unpaired $t$ tests.

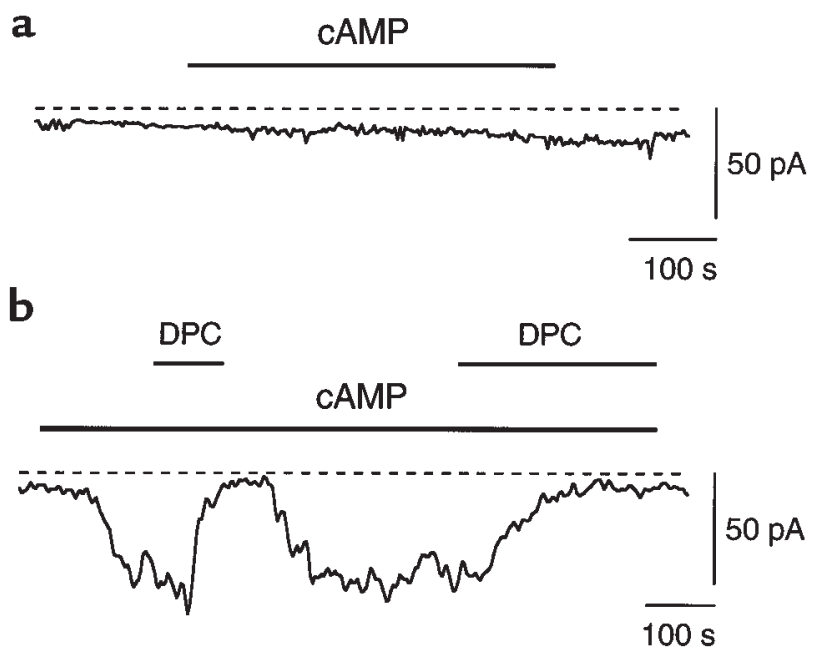

Figure 2

Differential activation of $\mathrm{Cl}^{-}$currents by cAMP in CFPAC-1 and PLJ-CFTR cell pairs. Examples of membrane currents recorded from a CFPAC-1 (a) and PLJ-CFTR (b) cell pair. Whereas exposure of PLJ-CFTR cells to $10 \mu \mathrm{m}$ forskolin, $500 \mu \mathrm{m}$ 8-Br-cAMP, and $500 \mu \mathrm{m}$ CPT-cAMP induced inward currents that could be blocked by 2 successive applications of $200 \mu \mathrm{M} \mathrm{DPC} \mathrm{(} n$ $=6$ ), the CAMP cocktail (CAMP) had no effect on membrane currents of CFPAC-1 cells. Note a small leakage current that developed with time in both traces. Bars indicate the duration of the drugs' superfusion. The bath solution is renewed every minute. Dashed lines indicate the zero current level.

$\mathbf{a}$
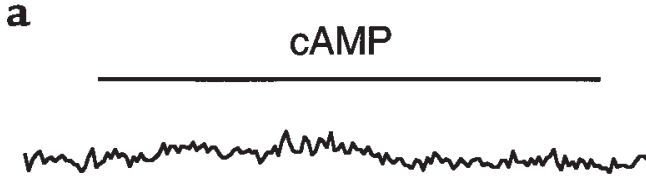

$1 \mathrm{nS}$

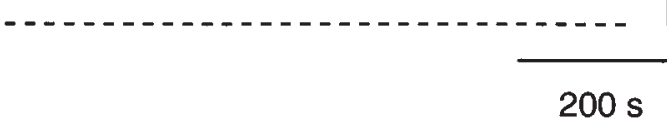

b

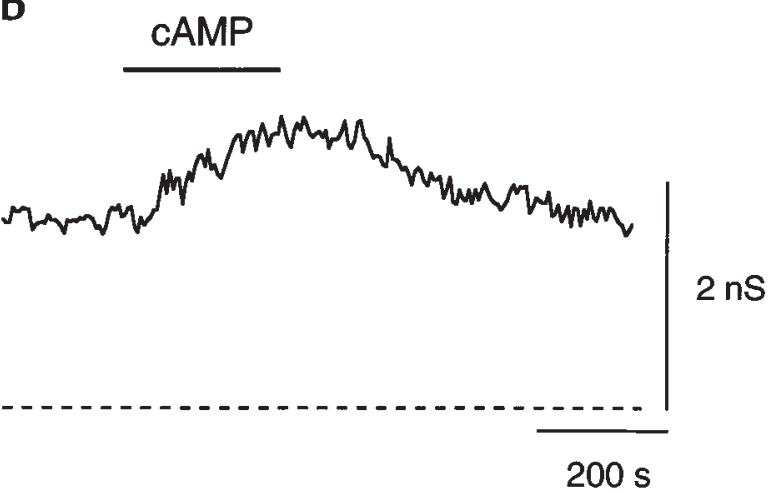

Figure 3

Differential effects of CAMP on junctional conductance of CFPAC-1 and PLJCFTR cell pairs. Examples of junctional conductances evaluated from a CFPAC-1 (a) and a PLJ-CFTR cell pair (b). Whereas exposure of PLJ-CFTR cells to $10 \mu \mathrm{M}$ forskolin, $500 \mu \mathrm{M}$ 8br-cAMP, and $500 \mu \mathrm{M}$ CPT-cAMP increased their electrical coupling in a reversible manner, the CAMP cocktail (cAMP) was without effect on junctional conductance of the CFPAC-1 cell pair. Bars indicate the duration of drugs superfusion. Dashed lines indicate the zero junctional conductance level. 


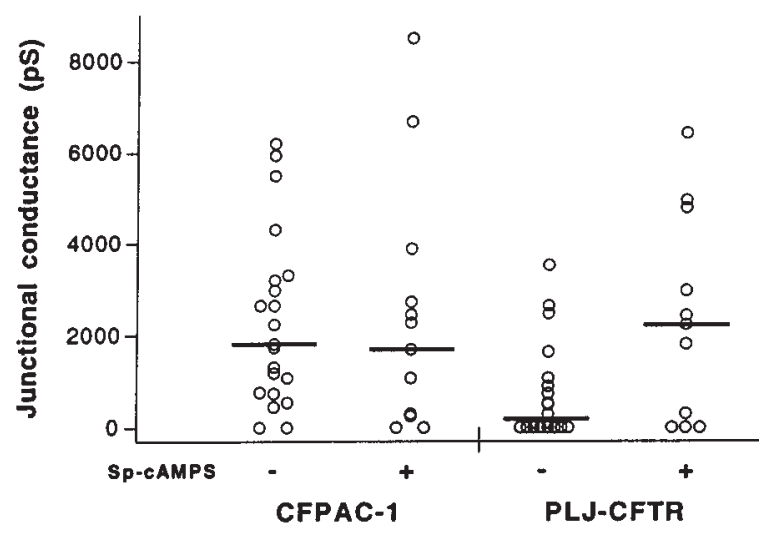

Figure 4

Distribution of junctional conductance values evaluated in CFPAC-1 and PLJ-CFTR cell pairs monitored under dual patch-clamp, with intracellular solutions supplemented or not with 20-100 $\mu \mathrm{M} \mathrm{S}_{\mathrm{p}}$-cAMPS. As shown, $\mathrm{S}_{\mathrm{p}}$-cAMPS did not affect junctional conductance of CFPAC-1 cells. In contrast, junctional conductance values of PLJ-CFTR cells, which are lower than those measured in parental cells, are markedly increased $(P<$ $0.05)$ in the presence of $S_{p}$-cAMPS in intracellular solutions. Bars represent the median values of junctional conductance.

\section{Results}

Expression of CFTR and connexins. The endogenous expression of CFTR mRNA could not be detected by RT-PCR in CFPAC-1 cells (Figure 1a, lane 3). In contrast, transcript for CFTR was detected in PLJ-CFTR cells (Figure 1a, lane 4) and in T84 cells, a colonic cell line that was used as a positive control (lane 2). SKHep1 cells, a hepatoma cell line devoid of CFTR, was used as a negative control (lane 5). To identify connexin mRNAs in CFPAC-1 and PLJ-CFTR cells, RT-PCRs were performed with specific primer pairs for $\mathrm{Cx} 26, \mathrm{Cx} 32, \mathrm{Cx} 37, \mathrm{Cx} 40$, $\mathrm{Cx} 43$, or $\mathrm{Cx} 45$. As shown in Figure 1a (lanes 8-10), only 1 amplification product corresponding to $\mathrm{Cx} 45 \mathrm{mRNA}$ was detected in both cell lines and in SKHep1 cells, the latter cell line being used as a positive control for this connexin (30). Cx45 mRNA was also detected in CAPAN cells (lane 6), another cell line also derived from human pancreatic duct cells, but not in T84 cells (lane 7), supporting a previous report (18).

The expression of $\mathrm{Cx} 45$ protein was confirmed by immunofluorescence labeling on CFPAC-1 and PLJ-CFTR cells using specific antibodies raised against $\mathrm{Cx} 45$ (27). As

\section{Table 1}

Fraction of CFPAC-1 and PLJ-CFTR cell populations that exhibited inward $\mathrm{Cl}^{-}$currents and increased junctional conductance in response to the cAMP cocktail

\begin{tabular}{lcc}
\hline & $\begin{array}{c}\text { cAMP-induced } \\
\text { inward currents }\end{array}$ & $\begin{array}{c}\text { cAMP-increased } \\
\text { junctional conductance }\end{array}$ \\
CFPAC-1 & $1 / 8(12.5)$ & $1 / 9(11)$ \\
PLJ-CFTR & $6 / 9(67)$ & $8 / 12(67)$ \\
\hline
\end{tabular}

AValues indicate the number of responding cells per total attempts. Percent values are given in parentheses. shown in Figure 1, b and c, punctate labeling at cell-cell contacts was observed in both cell lines. In keeping with the RT-PCR data, no immunolabeling for Cx26, Cx32, $\mathrm{Cx} 37, \mathrm{Cx} 40$, and $\mathrm{Cx} 43$ was detected (data not shown).

Effect of cAMP on CFTR-dependent $\mathrm{Cl}^{-}$currents in CF and CFTR-corrected cells. cAMP-dependent $\mathrm{Cl}^{-}$currents were searched for in single CFPAC-1 cells under whole-cell patch-clamp conditions. As expected, exposure of CFPAC1 cells to agents that elevate the intracellular cAMP concentration, a mixture of $500 \mu \mathrm{M}$ 8-Br-cAMP, $500 \mu \mathrm{M}$ CPTcAMP, and $10 \mu \mathrm{M}$ forskolin (hereafter referred to as the cAMP cocktail), did not evoke $\mathrm{Cl}^{-}$currents (Figure $2 \mathrm{a}$ ) in $87.5 \%$ of the cells studied (Table 1 ). Only in 1 CFPAC- 1 cell was a small cAMP-activated inward current observed. The expression of wild-type CFTR in CFPAC-1 cells has been shown to restore cAMP-dependent activation of $\mathrm{Cl}^{-}$currents $(10,25)$. As shown in Figure $2 \mathrm{~b}$ and Table 1 , the cAMP cocktail evoked inward currents in $6(67 \%)$ of 9 PLJCFTR cells studied. These currents were ascertained to be carried by $\mathrm{Cl}^{-}$, as they were blocked by DPC (Figure 2b), a $\mathrm{Cl}^{-}$channel blocker (28).

Effects of cAMP on gap junctional coupling in CF and CFTRcorrected cells. The strength of intercellular communication in CFPAC-1 and PLJ-CFTR cells was first examined by injection of Lucifer yellow ( $\mathrm{mol} \mathrm{wt}=443)$, a negatively charged fluorescent dye. In most cases, however, the tracer remained restricted to the injected cells, indicating absence of dye coupling. Exposure of the cells to agents that elevate intracellular cAMP did not change the extent of dye coupling (Table 2). Similar results were obtained with positively charged tracers of smaller radius, such as propidium iodide ( $\mathrm{mol} \mathrm{wt}=414 ; n=4)$ and neurobiotin $(\mathrm{mol} \mathrm{wt}=287 ; n=4)$ (data not shown).

Despite the absence of dye coupling, electrical coupling could be detected in about 100 pairs of CFPAC-1 and PLJ-CFTR cells. Although the magnitude of gap junctional conductance $\left(g_{j}\right)$ was variable in both cell lines, $g_{j}$ remained stable throughout the recordings (from 5 to 45 minutes) and could be blocked in a reversible manner by halothane $(n=5)$. To evaluate the effects of elevation of intracellular cAMP on electrical coupling, pairs of CFPAC-1 cells were exposed to the cAMP cocktail while monitoring $g_{j}$ as a function of time. As shown in Figure $3 a$ and Table 1, no changes in $g_{j}$ were observed in $89 \%$ of the CFPAC-1 cell pairs studied. In contrast, the cAMP cocktail markedly increased $g_{j}$ in 8 of 12 PLJ-CFTR pairs studied (Figure $3 \mathrm{~b}$ and Table 1 ). The cAMP-induced changes in $\mathrm{g}_{j}$, which represent an increase

\section{Table 2}

Extent of dye coupling between CFPAC-1 and PLJ-CFTR cells

\begin{tabular}{ccccc}
\hline & \multicolumn{2}{c}{ CFPAC-1 } & \multicolumn{2}{c}{ PLJ-CFTR } \\
Number of labeled cells & Control $^{\mathrm{A}}$ & cAMPB & Control & cAMP \\
$1-2$ & $21(80.8)$ & $11(84.6)$ & $13(86.7)$ & $20(95.2)$ \\
$3-4$ & $1(3.8)$ & $0(0)$ & $2(13.3)$ & $1(4.8)$ \\
$>5$ & $4(15.4)$ & $2(15.4)$ & $0(0)$ & $0(0)$ \\
\hline
\end{tabular}

${ }^{A}$ Values indicate the number of microinjected clusters. Virtually no spread of Lucifer yellow was observed between CFPAC-1 and PLJ-CFTR cells. Bncubation of both cell lines for 10-30 minutes with the cAMP cocktail did not change $(P>0.05)$ the extent of dye coupling. Percent values are given in parentheses. 
of $43 \pm 9 \%(n=8)$ of the initial junctional conductance, were fully reversible after removal of the cAMP cocktail from the superfusing solution (Figure $3 \mathrm{~b}$ ).

A limitation of superfusing membrane-permeant cAMP analogues is that their effective intracellular concentration cannot be controlled, and nonspecific effects on other signaling pathways thus cannot be ruled out. To specifically activate PKA, $100 \mu \mathrm{M} \mathrm{S}$-cAMPS was directly added to the intracellular solution. In these experiments, $g_{j}$ was evaluated 2-3 minutes after establishment of the dual whole-cell recording to allow diffusion of the PKA agonists into the cytosol (Figure 4). Under control conditions, CFPAC-1 cell pairs showed variable $\mathrm{g}_{\mathrm{j}}$ values with a median at $1,820 \mathrm{pS}$, whereas lower conductances were measured in PLJ-CFTR cell pairs (median: $195 \mathrm{pS}$ ). In the presence of $\mathrm{S}_{\mathrm{p}}$-cAMPS in the intracellular solution, no change in the distribution of $g_{j}$ values was observed in CFPAC-1 pairs (median: $1,690 \mathrm{pS})$. In contrast, PLJ-CFTR cell pairs showed increased $(P<0.05) \mathrm{g}_{\mathrm{j}}$ values with a median of 2,230 pS. These observations strongly suggest that cAMP regulates gap junctional communication in PLJ-CFTR but not in parental CFPAC-1 cells. The effect of extracellular ATP (a potent autacoid agonist) on electrical coupling was also studied. No changes of $g_{j}(n=7)$ were observed in CFPAC-1 and PLJ-CFTR cell pairs monitored in the presence of $10 \mu \mathrm{M}$ ATP (data not shown).

Effects of cAMP on single gap junction channels in CF and CFTR-corrected cells. To examine the effects of cAMP on single gap junction channel activity, large driving forces were applied to cell pairs exhibiting low $g_{j}$ or to pairs in which $g_{j}$ was reduced with halothane. As shown in Figure 5a, the activity of single gap junction channels was discriminated from that of other channels as steplike changes of opposite polarities but identical amplitudes recorded simultaneously in both current traces. The singlechannel conductances $\left(\gamma_{\mathrm{j}}\right)$ of these unitary events were measured, and frequency histograms were constructed. As shown in Figure 5b (top), no difference was observed in the distribution of $\gamma_{j}$ values between CFPAC-1 and PLJ-CFTR cell pairs. Both cell lines expressed a single population of gap junction channels that could be described by Gaussian relations with peak values at $30.8 \pm 0.1 \mathrm{pS}$ for CFPAC- 1 cells and $33.2 \pm 0.1 \mathrm{pS}$ for PLJ-CFTR cells. To determine whether these distributions were changed by an elevation in intracellular cAMP, $\gamma_{j}$ activity was studied in cell pairs dialyzed with $\mathrm{S}_{\mathrm{p}}$-cAMPS. Figure $5 \mathrm{~b}$ (bottom) shows that PKA agonists did not change the distribution of $\gamma_{j}$ values measured in either CFPAC-1 or PLJ-CFTR cell pairs. Indeed peak values of $31.1 \pm 0.3 \mathrm{pS}$ and $29.1 \pm 0.1 \mathrm{pS}$, which are not different from control values, were respectively measured in both cell lines.

In an attempt to explore the mechanisms that underlie the increase in sensitivity to cAMP of $g_{j}$, we studied the effect of the cAMP cocktail in PLJ-CFTR cell pairs exposed to the $\mathrm{Cl}^{-}$channel blocker DPC. Although DPC $(200-500 \mu \mathrm{M})$ reduced $g_{j}$ by $49 \pm 9 \%(n=10)$, this effect was apparently unrelated to the expression of CFTR, as it could be observed in both CFPAC- 1 and PLJ-CFTR cells. In the continuous presence of DPC, the cAMP cocktail was still able to increase $g_{j}$ by $31 \pm 8 \%$ in 3 of 6 PLJ-CFTR cell pairs. In addition, the cAMP cocktail markedly increased the activity of single gap junction channels in 4 other pairs. As shown in Figure 6, few channel openings could be recorded in a PLJ-CFTR cell pair exposed to 500 $\mu \mathrm{M}$ DPC. When the cAMP cocktail was added to the superfusing solution, single-channel activity increased, as indicated by frequent current transitions from the closed a

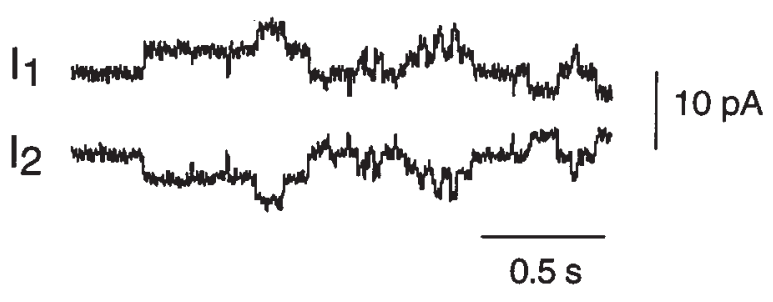

b
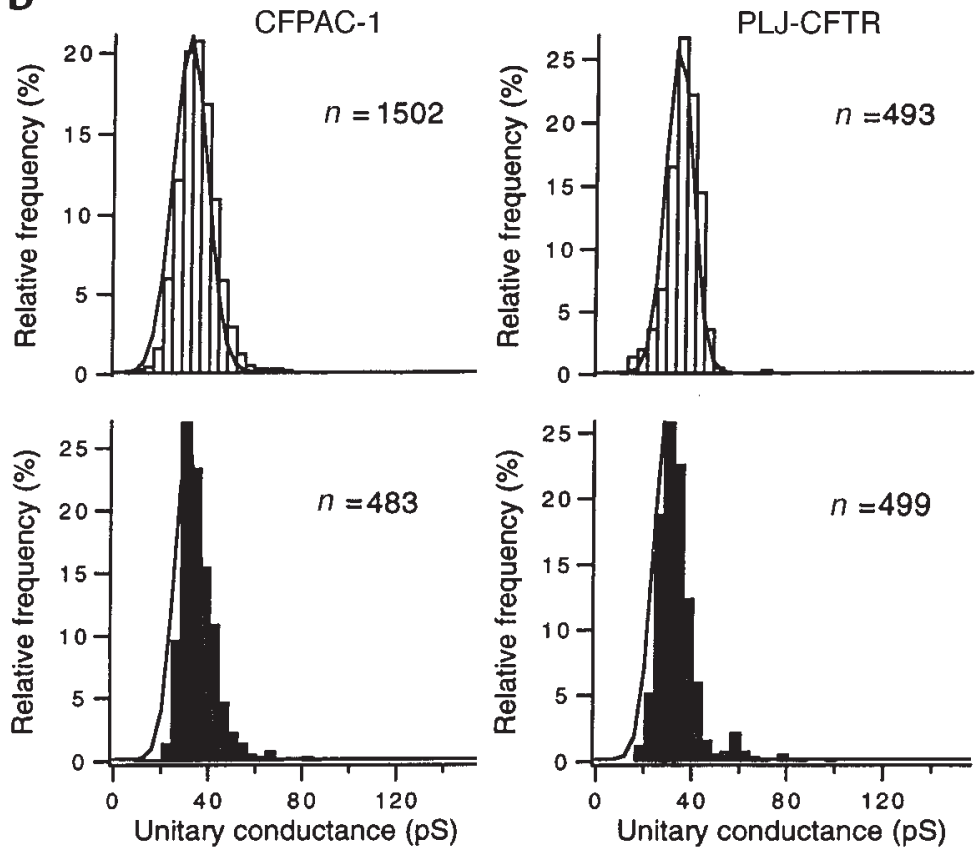

Figure 5

Unitary conductance of the gap junction channels expressed in CFPAC-1 and PLJ-CFTR cells. (a) Example of gap junction channel activity in a CFPAC-1 cell pair that was monitored in the presence of halothane. Transitions of similar amplitudes but opposite polarities were recorded in both current traces $\left(I_{1}\right.$ and $\left.I_{2}\right)$ during a $75-\mathrm{mV}$ transjunctional potential. (b) Frequency distribution of transitions measured in CFPAC-1 (left) and PLJCFTR (right) cell pairs monitored under control conditions (open bars) or in the presence of $S_{p}$-cAMPS (filled bars). Both cell types showed 1 distribution of conductance values that could be described by Gaussian relation (solid lines). The latter distributions were not affected by $100 \mu \mathrm{m} \mathrm{S}_{\mathrm{p}}$-cAMPS added to the pipette solution. 


\section{DPC}
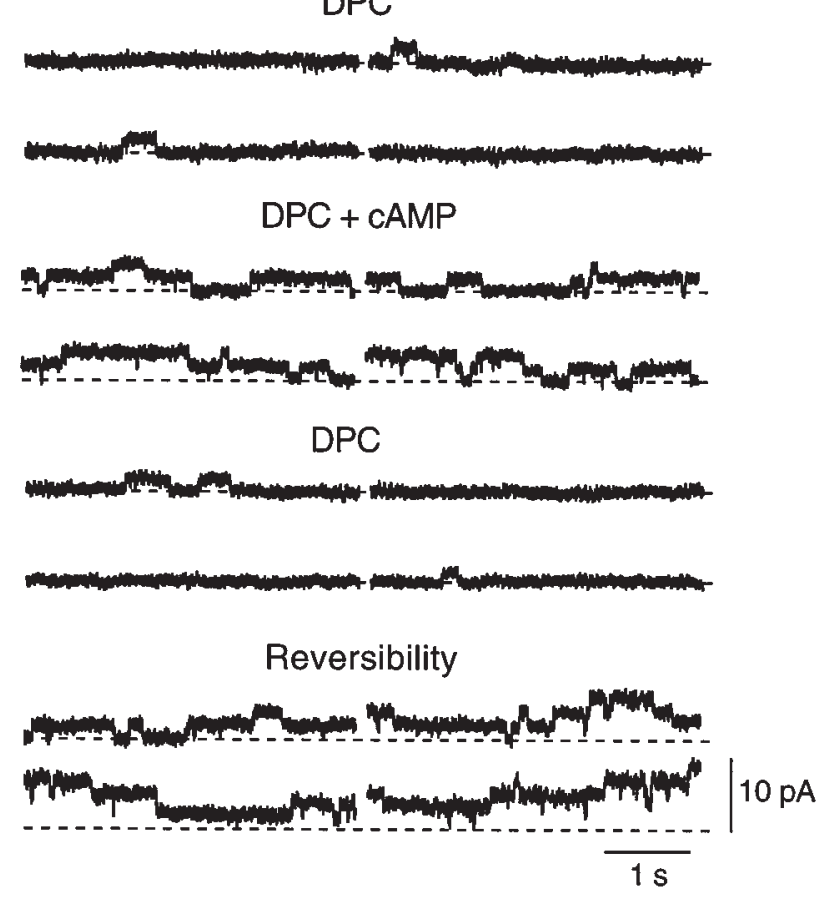

Figure 6

Effects of cAMP on gap junction channel activity in a PLJ-CFTR cell pair. Traces represent junctional currents recorded under stationary conditions at a transjunctional potential of $55 \mathrm{mV}$. Four successive sweeps per experimental condition are shown. In the presence of $500 \mu \mathrm{m}$ DPC, the channels remained closed almost all the time, with brief opening events (upward current deflections) being only occasionally detected. Addition of the cAMP cocktail (DPC + cAMP) increased the number of current transitions to the first and second levels of channel openings. Singlechannel activity was again decreased when cAMP was omitted from the superfusing solution. Multiple levels of channel activity were rapidly detected as soon as DPC was washed out (Reversibility). Dashed lines represent the zero junctional current level.

state to the first and second levels of channel openings. Single-channel activity decreased again when the cAMP cocktail was removed from the DPC-containing superfusing solution. The activity of multiple gap junction channels was restored after washing out DPC from the bathing solution (Figure 6).

\section{Discussion}

Our results describe the strength of gap junctional communication in a CF cell line and in the same cell line in which the defect was corrected by functional expression of CFTR. Whereas no $\mathrm{Cl}^{-}$currents and no changes in $\mathrm{g}_{\mathrm{j}}$ were observed in CF cells exposed to agents elevating intracellular cAMP concentration, the expression of CFTR was found to restore cAMP-dependent activation of both nonjunctional and junctional conductances.

The CFPAC-1 cells, which derive from a pancreatic duct adenocarcinoma of a patient with CF, express low levels of $\triangle F 508$ CFTR mRNA and thereby failed to generate $\mathrm{Cl}^{-}$currents in response to cAMP (24). In contrast, PLJ-CFTR cells, a clone of CFPAC-1 cells transfected with a retroviral vector containing the wild-type CFTR cDNA, exhibited $\mathrm{Cl}^{-}$currents in response to cAMP (25). In symmetrical $\mathrm{Cl}^{-}$conditions, we found that $67 \%$ of the PLJCFTR cell population showed inward currents in response to cAMP that could be inhibited by the $\mathrm{Cl}^{-}$ channel blocker DPC. The functional expression of CFTR in CFPAC-1 cells has also been associated with cAMP-dependent restoration of membrane recycling and activation of $\mathrm{K}^{+}$currents $(10,31)$. Therefore, the CFPAC-1/PLJ-CFTR cells appear to represent a valid model to study the relationship between CFTR expression and modulation of gap junction-mediated intercellular communication.

Gap junction channels are composed of 12 subunits called connexins, which are members of a large family of homologous proteins $(32,33)$. Each gap junction channel type is characterized by intrinsic properties and differential sensitivities to modulation by intracellular signaling pathways $(21,26,34,35)$. Although modulation of cell-cell communication at the transcriptional and translational levels by cAMP has been extensively reported, some studies have documented the short-term modulation of junctional coupling during PKA activation (21, 34-37). Here we have demonstrated that cAMP increased gap junctional conductance within minutes in pairs of cells expressing wild-type CFTR. This effect, which was induced by agents that either elevate intracellular cAMP or activate PKA, was not observed in cells harboring the $\triangle$ F508 mutation in CFTR. The increase in junctional conductance was observed in $67 \%$ of the PLJ-CFTR cell pairs studied, a fraction of the cell population that is similar to that developing $\mathrm{Cl}^{-}$currents in response to cAMP. The possibility that differential connexin expression underlies this difference in the cAMP effect is unlikely, as only Cx45 could be detected by RT-PCR and immunolabeling in both cell lines. Our results suggest, therefore, that expression of a functional CFTR protein in CFPAC- 1 cells is associated with recovery of the cAMP-dependent regulation of $\mathrm{Cx} 45$-mediated gap junctional coupling.

We observed that the average strength of electrical coupling was higher between CFPAC-1 cells compared with that measured in PLJ-CFTR cells. The possibility that both cell lines express different basal levels of $\mathrm{Cx} 45$ cannot be ruled out. Alternatively, wild-type CFTR may depress basal cell-cell coupling. In this context, the rapidly reversible effect of cAMP on $g_{j}$ suggests that inoperative gap junction channels are present in or near the junctional membranes of PLJ-CFTR cells and that cAMP allows their activation. An increase in cell-cell coupling might reflect a change in their unitary conductances or a change in their activity. Previous studies have shown that unitary gap junction channel conductance can be regulated by phosphorylating treatments. Although $\mathrm{Cx} 45$ is a phosphoprotein (30), exposure to agents leading to PKA activation had no effect on the level of phosphorylation or unitary conductances of $\mathrm{Cx} 45$ channels expressed in SKHep1 and HeLa cells $(26,38)$. Although the unitary gap junctional conductances recorded in PLJ-CFTR were not affected, single-channel activity was markedly increased in the presence of CAMP. This suggests that the increase of electrical coupling in PLJ-CFTR cells may be caused by a change in the open probability of the $\mathrm{Cx} 45$ channels or by a change in the rate of assembly/degrada- 
tion of connexons at gap junctional membranes. In any case, the latter effect appeared to depend on the presence of functional CFTR in the cell membrane.

The links between the expression of a CFTR protein and the modulation of gap junction channels are not known. A large body of evidence indicates that CFTR acts as a regulator of transcellular ion transport in epithelial cells (6-14). For example, CFTR has been shown to upregulate the activity of ORCC channels and to downregulate that of $\mathrm{ENaC}$ channels $(6,39)$. Hypotheses trying to explain the mechanisms by which CFTR regulates the activity of other ion channels include direct protein-protein interactions and/or the transport of ATP out of the cells, which would in turn activate purinergic membrane receptors $(9,40-42)$. Direct interactions between CFTR and gap junction channels appear unlikely because of their differential localization in the epithelial membrane. The possibility of an autocrine mechanism was also ruled out because exposure of CFPAC- 1 and PLJ-CFTR cells to ATP did not change their extent of electrical coupling. Since blockade of ion fluxes through CFTR channels with DPC did not prevent the modulation of $\mathrm{g}_{\mathrm{J}}$ by cAMP, it is conceivable that CFTR may associate with an intracellular factor that is necessary for basal and/or cAMP-dependent regulation of gap junction channels. Gap junctions are dynamic structures with short half-lives. Increasing evidence indicates that modifications of connexins, such as phosphorylation, dephosphorylation, and ubiquitination, may facilitate their incorporation to and/or retrieval from the membrane (43-47). Whether abnormal targeting of connexins for assembly/degradation is responsible for the differential regulation of gap junctional communication by CF cells remains to be investigated.

The pathophysiological consequences of CFTR as a regulator of intercellular communication in epithelial cells are unclear. Numerous studies have documented that perturbation of gap junctional communication in tissues known to be sites of CF manifestations is associated with the dysfunction of epithelial cells. For example, blockade of gap junctional communication alters the synchronized ciliary beating of tracheal cells and enhances the basal release of digestive enzymes by pancreatic acinar cells $(23,48)$. The CFPAC-1/PLJ-CFTR lines are known to have retained typical features of the native cells from which they derived $(24,25)$. Our finding that expression of CFTR is necessary for regulation of junctional conductance strongly suggests that cell-cell coupling is involved in the coordination of fluid secretion by the pancreatic duct epithelium. Consequently, the defective regulation of intercellular communication in human CF duct cells may contribute to certain clinical manifestations of the disease. Future studies should determine whether defect in gap junctional coupling regulation is a common feature in CF epithelia.

\section{Acknowledgments}

We thank N. Guérineau, M. Morris, and B. Kwak for their invaluable help during the preparation of this work. The technical assistance of I. Moix and T. Dudez is gratefully acknowledged. We thank S. Coppen, E. Dupont, and N.J. Severs for help and advice on localization of $\mathrm{Cx} 45$, provision of antibody, and discussion. We also thank Bochaton-Piallat, J.-C. Rumberli, and P. Meda for the use of their equipment and facilities. This work was supported by grants from the Swiss National Science Foundation (32.34086.95), l'Association Française de Lutte contre la Mucoviscidose, and the Schweizerische Gesellschaft für Cystische Fibrose.

1. Boat, T.M., Welsh, M.J., and Beaudet, A.L. 1989. Cystic fibrosis. In The metabolic basis of inherited disease. C.R. Scriver, A.L. Beaudet, W.S. Sly, and D. Valle, editors. McGraw-Hill. New York, NY. 2649-2680.

2. Kerem, B.-S., et al. 1989. Identification of the cystic fibrosis gene: genetic analysis. Science. 245:1073-1080.

3. Riordan, J.R., et al. 1989. Identification of the cystic fibrosis gene: cloning and characterization of complementary DNA. Science. 245:1066-1073.

4. Anderson, M.P., et al. 1991. Demonstration that CFTR is a chloride channel by alteration of its anion selectivity. Science. 253:202-205.

5. Bear, C.E., et al. 1992. Purification and functional reconstitution of the cystic fibrosis transmembrane conductance regulator (CFTR). Cell. 68:809-818.

6. Egan, M., et al. 1992. Defective regulation of outwardly rectifying chloride channels by protein kinase A corrected by insertion of CFTR. Nature. 358: 581-584.

7. Gabriel, S.E., Clarke, L.L., Boucher, R.C., and Stutts, M.J. 1993. CFTR and outwardly rectifying chloride channels are distinct proteins with a regulatory relationship. Nature. 363:263-266.

8. Schwiebert, E.M., Flotte, T., Cutting, G.R., and Guggino, W.B. 1994. Both CFTR and outwardly rectifying chloride channels contribute to cAMPstimulated whole cell chloride currents. Am. J. Physiol. 266:C1464-C1477.

9. Stutts, M.J., et al. 1995. CFTR as a cAMP-dependent regulator of sodium channels. Science. 269:847-850.

10. Loussouarn, G., Demolombe, S., Mohammad-Panah, R., Escande, D., and Baro, I. 1996. Expression of CFTR controls cAMP-dependent activation of epithelial K ${ }^{+}$currents. Am. J. Physiol. 271:C1565-C1573.

11. Stutts, M.J., Rossier, B.C., and Boucher, R.C. 1997. Cystic fibrosis transmembrane conductance regulator inverts protein kinase A-mediated regulation of epithelial sodium single channel kinetics. J. Biol. Chem. 272:14037-14040.

12. McNicholas, C.M., et al. 1996. Sensitivity of a renal $\mathrm{K}^{+}$channel (ROMK2) to the inhibitory sulfonylurea compound glibenclamide is enhanced by coexpression with the ATP-binding cassette transporter cystic fibrosis transmembrane conductance regulator. Proc. Natl. Acad. Sci. USA. 23:8083-8088.

13. Hogan, D.L., et al. 1997. CFTR mediates cAMP- and Ca ${ }^{2+}$-activated duodenal epithelial $\mathrm{HCO}_{3}{ }^{-}$secretion. Am. J. Physiol. 272:G872-G878.

14. Seidler, U., et al. 1997. A functional CFTR protein is required for mouse intestinal cAMP-, cGMP-, and $\mathrm{Ca}^{2+}$-dependent $\mathrm{HCO}_{3}{ }^{-}$secretion. J. Physiol. (Lond.) 505:411-423.

15. Johnson, L.G., et al. 1992. Efficiency of gene transfer for restoration of normal airway epithelial function in cystic fibrosis. Nat. Genet. 2:21-25.

16. Zabner, J., Couture, L.A., Smith, A.E., and Welsh, M.J. 1994. Correction of cAMP-stimulated fluid secretion in cystic fibrosis airway epithelia: efficiency of adenovirus-mediated gene transfer in vitro. Hum. Gene Ther. 5:585-593.

17. Banoub, R.W., Fernstrom, M., Malkinson, A.M., and Ruch, R.J. 1996. Enhancement of gap junctional intercellular communication by dibutyryl cyclic AMP in lung epithelial cells. Anticancer Res. 16:3715-3719.

18. Chanson, M., White, M.M., and Garber, S.S. 1996. cAMP promotes gap junctional coupling in T84 cells. Am. J. Physiol. 271:C533-C539.

19. Brezillon, S., et al. 1997. ATP depletion induces a loss of respiratory epithelium functional integrity and down-regulates CFTR (cystic fibrosis transmembrane conductance regulator) expression. J. Biol. Chem. 272:27830-27838.

20. Boitano, S., Dirksen, E.R., and Sanderson, M.J. 1992. Intercellular propagation of calcium waves mediated by inositol trisphosphate. Science. 258:292-295.

21. Saèz, J.C., Berthoud, V.M., Moreno, A.P., and Spray, D.C. 1993. Gap junctions: multiplicity of controls in differentiated and undifferentiated cells and possible functional implications. In Advances in second messenger and phosphoprotein research. S. Shenolikar and A.C. Nairn, editors. Raven Press. New York, NY. 163-198.

22. Meda, P. 1996. The role of gap junction membrane channels in secretion and hormonal action. J. Bioenerg. Biomembr. 28:369-377.

23. Sanderson, M.J. 1996. Intercellular waves of communication. News in Physiological Sciences. 11:262-269.

24. Shoumacher, R.A., et al. 1990. A cystic fibrosis pancreatic adenocarcinoma cell line. Proc. Natl. Acad. Sci. USA. 87:4012-4016.

25. Drumm, M.L., et al. 1990. Correction of the cystic fibrosis defect in vitro by retrovirus-mediated gene. Cell. 62:1227-1233.

26. Kwak, B.R., et al. 1995. Differential regulation of distinct types of gap junction channels by similar phosphorylating conditions. Mol. Biol. Cell. 6:1707-1719.

27. Coppen, S.R., Dupont, E., Rothery, S., and Severs, N.J. 1998. Connexin 45 expression is preferentially associated with the ventricular conduction 
system in mouse and rat heart. Circ. Res. 82:232-243.

28. Cliff, W.H., Schoumacher, R.A., and Frizzell, R.A. 1992. Cyclic AMP-activated chloride channels in CFTR-transfected cystic fibrosis pancreatic epithelial cells. Am. J. Physiol. 262:C1154-C1160.

29. Burt, J.M., and Spray, D.C. 1988. Single channel events and gating behavior of the cardiac gap junction channel. Proc. Natl. Acad. Sci. USA. 85:3421-3434.

30. Laing, J.G., Westphale, E.M., Engelmann, G.L., and Beyer, E.C. 1994. Characterization of the gap junction protein, connexin45. J. Membr. Biol. 139:31-40.

31. Bradbury, N.A., et al. 1992. Regulation of plasma membrane recycling by CFTR. Science. 256:530-532.

32. Kumar, N.M., and Gilula, N.B. 1996. The gap junction communication channel. Cell. 84:381-388.

33. Goodenough, D.A., Goliger, J.A., and Paul, D.L. 1996. Connexins, connexons, and intercellular communication. Annu. Rev. Biochem 65:475-502.

34. Bruzzone, R., White, T.W., and Paul, D.L. 1996. Connections with connexins: the molecular basis of direct intercellular signaling. Eur. J. Biochem. 238:1-27.

35. Stagg, R.B., and Fletcher, W.H. 1990. The hormone-induced regulation of contact-dependent cell-cell communication by phosphorylation. Endocr. Rev. 11:302-325.

36. Mehta, P.P., Yamamoto, M., and Rose, B. 1992. Transcription of the gene for the gap junctional protein connexin 43 and expression of functional cell-to-cell channels are regulated by cAMP. Mol. Biol. Cell. 3:839-850.

37. Atkinson, M.M., et al. 1995. Cyclic AMP modifies the cellular distribution of connexin 43 and induces a persistent increase in the junctional permeability of mouse mammary tumor cells. J. Cell Sci. 108:3079-3090.

38. Butterweck, A., Gergs, U., Elfgang, C., Willecke, K., and Traub, O. 1994. Immunochemical characterization of the gap junction protein connex- in 45 in mouse kidney and transfected human HeLa cells. J. Membr. Biol. 141:247-256

39. Chinet, T.C., Fullton, J.M., Yankaskas, J.R., Boucher, R.C., and Stutts, M.J. 1994. Mechanism of sodium hyperabsorption in cultured cystic fibrosis nasal epithelium: a patch-clamp study. Am. J. Physiol. 266:C1061-C1068.

40. Kunzelmann, K., Kiser, G.L., Schreiber, R., and Riordan, J.R. 1997. Inhibition of epithelial $\mathrm{Na}^{+}$currents by intracellular domains of the cystic fibrosis transmembrane conductance regulator. FEBS Lett. 400: 341-344.

41. Schwiebert, E.M., et al. 1995. CFTR regulates outwardly rectifying chloride channels through an autocrine mechanism involving ATP. Cell. 81:1063-1073.

42. Sugita, M., Yue, Y., and Foskett, J.K. 1998. CFTR Cl--channel and CFTRassociated ATP channel: distinct pores regulated by common gates. EMBO J. 17:989-908.

43. Musil, L.S., and Goodenough, D.A. 1991. Biochemical analysis of connexin43 intracellular transport, phosphorylation, and assembly into gap junctional plaques. J. Cell Biol. 115:1357-1374.

44. Lampe, P. 1994. Analyzing phorbol ester effect on gap junctional communication: dramatic inhibition of assembly. J. Cell Biol. 127:1895-1905.

45. Laing, J.G., Tadros, P.N., Westphale, E.M., and Beyer, E.C. 1997. Degradation of connexin 43 gap junctions involves both the proteasome and the lysosome. Exp. Cell Res. 236:482-492.

46. Beardslee, M.A., Laing, J.G., Beyer, E.C., and Saffitz, J.E. 1998. Rapid turnover of connexin43 in the adult rat heart. Circ. Res. 83:629-635.

47. Hertlein, B., Butterweck, A., Haubrich, S., Willecke, K., and Traub, O. 1998. Phosphorylated carboxy terminal serine residues stabilize the mouse gap junction protein connexin45 against degradation. J. Membr. Biol. 162:247-257.

48. Chanson, M., et al. 1998. Enhanced secretion of amylase from exocrine pancreas of connexin32-deficient mice. J. Cell Biol. 141:1267-1275. 